\title{
RELEVANCIA DOS TRABALLOS METEOROLÓXICOS DE DOMINGO FONTÁN RODRÍGUEZ*
}

\author{
IVÁN FERNÁNDEZ PÉREZ \\ Universidade de Santiago de Compostela \\ ORCID iD: http://orcid.org/0000-0002-1078-9186
}

\begin{abstract}
* Agradecementos: Quero agradecer a César Camargo Sánchez, vicepresidente da Fundación Domingo Fontán, a súa boa disposición para facer posible este traballo, tanto pola remisión das medidas meteorolóxicas efectuadas por Fontán como na resolución de dúbidas que foron xurdindo. Así mesmo, agradezo a José Ángel Docobo Durántez, catedrático de Astronomía da Universidade de Santiago de Compostela, os seus comentarios sobre o traballo.
\end{abstract}

Copyright: (C) 2021 CSIC. La edición electrónica de esta revista se distribuye bajo los términos de una licencia de uso y distribución Creative Commons Reconocimiento 4.0 Internacional (CC BY 4.0).

Cómo citar/Citation: Iván FernÁndez Pérez, "Relevancia dos traballos meteorolóxicos de Domingo Fontán Rodríguez", Cuadernos de Estudios Gallegos, 68, núm. 134 (2021), págs. 361-393, https://doi.org/10.3989/ceg.2021.134.12 


\section{RELEVANCIA DOS TRABALLOS METEOROLÓXICOS DE DOMINGO FONTÁN RODRÍGUEZ}

\section{RESUMO}

Aínda que é habitual considerar a Domingo Fontán Rodríguez como matemático, político, xeógrafo ou cartógrafo, este persoeiro destacou tamén noutros campos da ciencia como a meteoroloxía. Pretendemos neste artigo amosar as achegas menos coñecidas de Fontán no ámbito da meteoroloxía, tanto dentro da Universidade de Santiago de Compostela como fóra dela, ademais de lembrar os seus principais datos biográficos.

Palabras ClaVe: Domingo Fontán, Meteoroloxía, Galicia, Século XIX.

\section{RELEVANCIA DE LOS TRABAJOS METEOROLÓGICOS DE DOMINGO FONTÁN RODRÍGUEZ}

\section{RESUMEN}

Aunque es habitual considerar a Domingo Fontán Rodríguez como matemático, político, geógrafo o cartógrafo, este personaje destacó también en otros campos de la ciencia como la meteorología. Pretendemos en este artículo mostrar las contribuciones menos conocidas de Fontán en el ámbito de la meteorología, tanto dentro de la Universidade de Santiago de Compostela como fuera de ella, además de recordar sus principales datos biográficos.

Palabras Clave: Domingo Fontán, Meteorología, Galicia, Siglo XIX.

\section{RELEVANCE OF THE METEOROLOGICAL WORKS OF DOMINGO FONTÁN RODRÍGUEZ}

\section{ABSTRACT}

Although it is common to consider Domingo Fontán Rodríguez as a mathematician, politician, geographer, or cartographer, this personage also stood out in other fields of science such as meteorology. In this article we aim to show Fontán's lesser known contributions in the field of meteorology, both inside and outside the University of Santiago de Compostela, as well as to go over his main biographical data.

KeY WORDS: Domingo Fontán, Meteorology, Galicia, XIX Century. 
Recibido/Received: 03/05/2020

Aceptado/Accepted: 15/11/2020

\section{CONTEXTO POLÍTICo E SOCIAL EN TEMPOS DE DOMINGo FontÁN}

O territorio galego, coñecido na idade moderna como Reino de Galicia, estaba dividido a finais do século XVIII en sete provincias (Santiago, A Coruña, Betanzos, Mondoñedo, Lugo, Ourense e Tui) e pasou en 1833 a ter as catro provincias actuais ${ }^{1}$. Rey Castelao indica ao respecto que a súa situación excéntrica e difícil acceso, facilitou que Galicia conservara unha forte identidade ${ }^{2}$.

Fernández Cortizo, citando traballos de Pérez García e de Eiras Roel, indica que en 1787, un ano antes do nacemento de Fontán, Galicia era un país pouco urbanizado, con cidades e vilas de pequeno tamaño. Contaba entón cuns 1400000 habitantes o que supoñía case o $13 \%$ da poboación española ${ }^{3}$. Ferrol era a cidade máis poboada con preto de 25000 habitantes, seguida de Santiago cuns 16600 e A Coruña cuns $13500^{4}$.

Durante o período que viviu Fontán a situación variou moito. En 1860 a poboación galega acadaba preto de 1800000 habitantes, pero a proporción con respecto á poboación española diminuíu situándose preto do 11,5\%. En 1857, A Coruña contaba cuns 27300 habitantes, Santiago tiña preto de 23000 e Ferrol veu diminuída a súa poboación ata os 17400 habitantes.

A posición de Ferrol a finais do século XVIII foi debida á creación en 1726 do Departamento Marítimo de Ferrol. A construción e desenvolvemento do Arsenal e distintos establecementos militares trouxeron a Ferrol a centos de persoas de gran cualificación que se deixou notar na comarca. Cos anos esta instalación foi languidecendo e perdendo pulo por distintas circunstancias, e A Coruña que era

\footnotetext{
${ }^{1}$ Nun curto período de tempo dentro do Trienio Liberal Galicia xa fora dividida nas provincias da Coruña, Lugo, Ourense e Vigo.

2 Ofelia Rey Castelao, "Espacio, Historia e Identidad de Galicia”, Historia de la Galicia Moderna: siglos XVI-XIX, Santiago de Compostela, Servizo de Publicacións e Intercambio Científico da Universidade de Santiago de Compostela, 2012, páx. 15.

3 Camilo Fernández Cortizo, "Población rural, mundo urbano y migraciones", Historia de la Galicia Moderna: siglos XVI-XIX, Santiago de Compostela, Servizo de Publicacións e Intercambio Científico da Universidade de Santiago de Compostela, 2012, páx. 40.

4 Fernández Cortizo, "Población rural...", páx. 66.
} 
a sede das principais institucións de representación da Coroa, tivo un gran crecemento especialmente polo desenvolvemento do comercio e pasou a ser a cidade de referencia de Galicia, mantendo Santiago o seu carácter cultural e relixioso.

Domingo Fontán Rodríguez viviu os últimos anos da Ilustración e a Guerra da Independencia (1808-1814), que liquidou en gran parte a vella estrutura política-administrativa de España (o antigo réxime) e abriu, coa instauración das Cortes de Cádiz (1810) que promulgaron a Constitución de 1812, un novo período (o novo réxime ou réxime constitucional) no que por primeira vez en España o pobo, con distintas visións políticas (liberais e absolutistas), tivo un certo rol como organismo lexislador.

A Ilustración foi un movemento que xurdiu en Europa no século XVIII que pretendía "iluminar" á sociedade a través da razón e "abandonar" o coñecemento baseado nos textos sagrados ou na tradición. Os ilustrados entendían que mediante a razón o ser humano coñecería mellor a realidade (a natureza) e compartindo este coñecemento, grazas á educación, acadaría o progreso e a felicidade. Respecto a este movemento, López López indica que a Ilustración foi un movemento que buscaba o progreso económico co fomento da agricultura, o comercio e a industria "popular", pero tamén o desenvolvemento cultural e educativo 5 . En Galicia non foi un movemento de rupturas drásticas, aínda que os ilustrados galegos si que alertaron dos problemas de Galicia e buscaron solucións a estes, e creáronse institucións como a Academia de Agricultura (1765), as Sociedades Económicas de Amigos del País de Santiago de Compostela e de Lugo (1774), e o Consulado do Mar da Coruña (1775), para fomentar a formación, desenvolver a economía e en definitiva dar resposta aos problemas de Galicia.

O liberalismo foi un movemento político partidario de que o novo réxime saíra adiante. Concretamente foi durante o Trienio Liberal (1820-1823) cando se aprobaron reformas neste sentido.

Fronte ao liberalismo, o absolutismo foi un movemento político que propugnaba á volta do antigo réxime onde o monarca abarcaba todo o poder e o pobo non tiña protagonismo. Durante o reinado de Fernando VII existiron dous períodos absolutistas, o primeiro entre 1814 e 1819 , e o segundo que comeza en 1823 e remata en $1833^{6}$, que é o ano do falecemento de Fernando VII e do fin do antigo réxime.

\footnotetext{
5 Roberto LÓPEz LóPEZ, "De la cultura material a la cultura letrada", Historia de la Galicia Moderna: siglos XVI-XIX, Santiago de Compostela, Servizo de Publicacións e Intercambio Científico da Universidade de Santiago de Compostela, 2012, páx. 404.

${ }^{6}$ Emilio GonzÁlez LóPeZ, Entre el Antiguo y el Nuevo Régimen: Absolutistas y Liberales. El reinado de Fernando VII en Galicia, Sada, Edicións do Castro, 1980, páx. 202.
} 
Pode dicirse que Domingo Fontán estaba de acordo cos ideais da Ilustración e tiña un pensamento liberal moderado. Embebido por estes movementos, buscou o progreso da súa terra, formando aos mozos nas ciencias e traballando a prol de avances na economía a través do desenvolvemento en diversos eidos como o comercio, a industria ou a agricultura, e sobre todo coa fixación de que era fundamental mellorar as comunicacións dentro de Galicia e desta coa meseta.

\section{DATOS BIOGRÁFICOS DE FONTÁN}

Os principais datos biográficos de Domingo Fontán que amosamos neste artigo poden verse entre outras publicacións no libro D. Domingo Fontán y su Mapa de Galicia: en el primer centenario de su publicación editado polo Instituto Padre Sarmiento de Estudios Gallegos, na monografía Vida y obra de Domingo Fontán escrita por Xosé Lois Vila Fariña ou no libro Domingo Fontán cuxo autor é Gonzalo Méndez Martínez. Tamén poden consultarse na web algunhas biografías como a de Margarita Barral Martínez para o Álbum de Galicia, a de Carmen Manso Porto para a Real Academia de Historia, así como as achegas de César Camargo Sánchez na web da Fundación Domingo Fontán e o seu blog asociado Cuadernos de Domingo Fontán.

\section{DOMINGO FONTÁN E A SÚA FORMACIÓN COMO CIENTÍFICO}

Fontán naceu en Porta do Conde no actual concello de Portas (provincia de Pontevedra) o 17 de abril do ano $1788^{7}$. A súa formación iníciase de neno co ensino das primeiras letras na parroquia de San Andrés de Baliñas e de latín no lugar de Búa, na freguesía de San Verísimo de Barro. Tamén recibiu formación do seu tío Sebastián Rodríguez Blanco (Porta do Conde 1761-Noia 1843). E cando este foi nomeado cura párroco de Noia no ano 1800, Domingo Fontán aproveitou as súas estadías estivais nesa vila para continuar a súa formación humanística co seu tío, e aprender francés e inglés da man de Nicolás Bretón, presbítero francés acollido por Sebastián Rodríguez, e posiblemente tamén doutros exiliados procedentes de Francia que fuxiron pola Revolución de 1789.

Na Universidade de Santiago de Compostela, Domingo Fontán comezou os seus estudos na Facultade de Artes e Filosofía o día de San Lucas de $1800^{8}$ con doce anos de idade e acadou o grao de bacharel en Artes en 1802. No curso académico 1802/1803 cursou terceiro de Filosofía ${ }^{9}$ da man de Manuel Gallego

\footnotetext{
7 Seus pais foron Rosendo Fontán Oliveira e Sebastiana Rodríguez Blanco.

${ }^{8}$ O equivalente actual ao inicio do curso académico 1800/1801.

${ }^{9}$ Concretamente a disciplina de física.
} 
Moreira. O curso seguinte comezou os estudos en Teoloxía, obtendo o grao de bacharel en 1810 e a licenciatura e doutoramento nesta disciplina en 1811. Por esas datas foi tamén profesor de idiomas na Escola Militar do IV Exército situado na capital compostelá.

En canto á formación científica, algúns biógrafos indican que Fontán acudiu durante dous cursos académicos (1812/1813 e 1813/1814) á cátedra de Matemáticas Sublimes impartida por José Rodríguez González (Santa María de Bermés 1770-Santiago de Compostela 1824), coñecido como o matemático do Bermés. No libro oficial de matrícula da Universidade de Santiago de Compostela que se conserva no Arquivo Histórico Universitario (AHUS) non aparece Fontán matriculado nesta disciplina ${ }^{10}$, Tampouco consta que Fontán tivese como mestre a Rodríguez a comezos de século cando preparaba o grao de bacharel en Artes. O máis probable foi que, entre 1812 e 1814, xurdiu unha boa sintonía entre eles e que intercambiaron ideas e pareceres de xeito habitual. Rodríguez debeu comentar con Domingo Fontán os últimos avances científicos que se estaban producindo en Europa e como introducir esas novidades na Universidade. Tamén deberon tratar os problemas que atinxían a Galicia como o das comunicacións para cuxa solución pasaba sen remedio por cartografar o territorio, aspecto no que Rodríguez era un bo coñecedor das técnicas necesarias para dita empresa, dada a súa experiencia na triangulación das illas Baleares. Así, Fontán formou unha copia da Memoria da Formación do Mapa de España ${ }^{11}$ que Rodríguez entregou en 1808 en Cádiz á Junta Central Suprema ${ }^{12}$ e decidiu comezar a súa grande obra a Carta Xeométrica de Galicia.

Ademais das achegas de Rodríguez, Fontán cultivou as ciencias de xeito autodidacta coa consulta dos principais tratados científicos da época elaborados por Delambre, Laplace, Biot, etc. posiblemente proporcionados por Rodríguez e que se conservan hoxe na Fundación Domingo Fontán.

Fontán non descoidou nunca a súa formación nin humanística nin científica, así despois de rematar os estudos de Teoloxía, cursou e obtivo os graos de licenciado en Filosofía (1813), doutor en Filosofía (1814), bacharel en Canons (1816) e bacharel en Leis $(1828)^{13}$, compaxinando estes estudos coas súas tarefas docentes.

\footnotetext{
10 AHUS, Matrículas 1812-1824, F.U., SH 296.

11 É descoñecido o paradoiro do orixinal desta Memoria e a copia citada consérvase actualmente na Fundación Domingo Fontán.

12 Órgano gubernativo formado en 1808 durante a ocupación francesa na Guerra da Independencia.

13 AHUS, Expedientes persoais, F.U., 4.208, Exp. 26.
} 


\section{Fontán, CATEdrático na Universidade de Santiago de Compostela}

Unha vez rematados os seus estudos en Teoloxía, Domingo Fontán foi nomeado profesor substituto no curso 1812/1813 na cátedra de Retórica propiedade de Antonio Sarmiento, e tivo como alumnos a Manuel Varela, Manuel Antonio Blanco, Josef Regueiro e Felipe María de Loreto ${ }^{14}$.

No curso seguinte de 1813/1814 Fontán sería substituto da cátedra de Lóxica e Metafísica, na que tivo 42 alumnos.

É a partir do curso académico seguinte (1814/1815) cando Fontán substitúe a Rodríguez na cátedra de Matemáticas Sublimes, dado que este último fora comisionado para visitar varios establecementos científicos en Alemaña e perfeccionarse no eido da mineraloxía, tendo ese ano como único alumno a Manuel Boán. Adoitaban ser poucos os alumnos desta disciplina. Máis numeroso eran os asistentes á cátedra de Elementos de Aritmética, Álxebra e Xeometría, polo seu carácter obrigatorio no plan de estudos de Artes e Filosofía. Nese ano foron 72 alumnos os que tivo Luis Pose Varela, profesor substituto desa materia.

Fontán continuou os cursos seguintes como profesor substituto de Matemáticas Sublimes. No curso académico 1815/1816 tivo como alumno a Juan de Ynsua y Pazos, e no 1816/1817 a Ramón Dionisio de la Sagra y Peris (A Coruña 1798-Neuchatel 1871), Casiano de Prado y Vallo (Santiago de Compostela 1797-Madrid 1866) e Juan Antonio del Río. Os dous primeiros terían posteriormente unha destacada traxectoria científica: De la Sagra como naturalista e economista, mentres que Casiano de Prado como enxeñeiro de minas e xeólogo (foi autor de mapas xeolóxicos de varias provincias), exercendo ambos os dous fóra de Galicia.

No seguinte curso académico de 1817/1818, Fontán figura como substituto na cátedra de Matemáticas (Elementais) que contaba con 182 alumnos ${ }^{15}$, mentres que na cátedra de Matemáticas Sublimes estaba Luis Pose Varela como substituto no libro de matrícula, aínda que non tivo ningún alumno. Neste curso foi cando Fontán gañou a cátedra de Matemáticas, vacante por ascenso de Joaquín Patiño. Nesta oposición competiu con Luis Pose Varela, José Fernández Losada, José Fernández Varela e Ramón Manuel Rodríguez; os xuíces foron Juan Francisco Gómez, Diego Mosquera, Ramón Herrera e Antonio María Mercado. Fontán defendeu unha disertación en latín baixo o título "Numeri universi determinato Linguali scriptoque idiomate exprimi possunt" ${ }^{\prime 6}$ que se conserva no Arquivo Histórico da Universidade de Santiago de Compostela.

\footnotetext{
14 AHUS, Matrículas 1812-1824, F.U., SH 296.

15 Dos cales suspendeu a 108 creándose unha certa polémica.

${ }^{16}$ AHUS, Artes y Filosofia, Cátedras, F.U., SH 406.
} 
Fontán exerceu dende entón dita cátedra en propiedade na Universidade de Santiago de Compostela ata o seu nomeamento en 1835 como director do Observatorio Astronómico de Madrid, agás no curso académico 1818/1819 que impartiu Física Experimental e entre 1823 e 1826, perseguido polo absolutismo por ocupar durante o Trienio Liberal o cargo de secretario da Deputación provincial de Galicia primeiro e da Coruña despois ${ }^{17}$. En 1830 gozou tamén de dispensa na asistencia a clase para rematar a Carta Xeométrica de Galicia.

\section{ANTECEDENTES DOS ESTUdOS METEOROLÓXICOS EN GALICIA}

Na Historia da meteoroloxía e da climatoloxía en Galicia, obra coordinada por Díaz-Fierros e publicada polo Consello da Cultura Galega, cítanse os primeiros traballos realizados sobre esta disciplina en Galicia por Francisco Cónsul Jove (1754-1810) e polo ferrolán José Alonso López de Nobal (1763-1824) ${ }^{18}$.

O asturiano Cónsul Jove foi membro da Sociedade Económica de Amigos del País de Santiago e tamén do Consulado da Coruña e publicou na revista $\mathrm{Hi}$ dráulica Rústica en 1788 unha estimación das precipitacións en Santiago a partir dos datos coñecidos de Londres e París.

Alonso López de Nobal foi director e profesor de Matemáticas na Academia de Gardas Mariñas de Ferrol e director do Observatorio Astronómico dependente da devandita Academia, na que se realizaron tanto medidas astronómicas como meteorolóxicas para a aprendizaxe dos gardas mariñas. Nas Consideraciones Generales sobre varios puntos históricos, políticos y económicos a favor de la libertad y fomento de los pueblos y noticias particulares de esta clase relativas a Ferrol y su comarca, publicadas por Alonso López de Nobal en 1820, recóllense entre outros moitos datos, un resumo de medidas de precipitación, temperatura, presión atmosférica e ventos recompiladas durante os anos de 1814 a $1817^{19}$.

A nivel instrumentación tense coñecemento de que o galego José María Baleato (1743-1801) construíu no Arsenal de Ferrol, a finais do século XVIII, varios barómetros e termómetros.

\footnotetext{
17 Fontán xa fora denunciado ante o Claustro, xunto co bibliotecario Joaquín Patiño e o doutor en medicina Juan Camiña, en maio de 1814 por liberal, da que foi absolto pola Real Audiencia de Galicia en xuño de 1815.

18 Francisco DíAz-Fierros Viqueira (coord.), Historia da meteoroloxía e da climatoloxía en Galicia, Santiago de Compostela, Consello da Cultura Galega, 2008, páx. 29.

19 Díaz-Fierros Viqueira (coord.), Historia da meteoroloxía..., páx. 30.
} 


\section{SITUACIÓN DA METEOROLOXÍA EN ESPAÑA}

No século XVIII xurdiron, impulsadas polo movemento ilustrado, algunhas iniciativas para a recollida de datos meteorolóxicos, entre as que cabe salientar as organizadas pola Real Academia Médico Matritense ou pola Real Academia de Ciencias y Artes de Barcelona, así como noutras academias médicas e nalgunhas sociedades económicas de amigos do país ${ }^{20}$. Tamén se recolleron rexistros no Observatorio da Armada en San Fernando (Cádiz) e a comezos do século XIX no Observatorio de Madrid.

Ao marxe das institucións e asociacións pódense salientar algunhas iniciativas máis ou menos individuais como as medicións realizadas entre finais do século XVIII e principios do XIX por Francisco Salvà i Campillo en Barcelona ou as feitas en Cádiz polos irmáns Urrutia entre 1820 e 1882 con algúns anos de interrupción ${ }^{21}$.

A meteoroloxía na época de Fontán tiña un carácter de ciencia auxiliar doutras disciplinas como a agricultura, a astronomía, a navegación marítima ou a medicina ${ }^{22}$. A mediados do século XIX creáronse na Península varias estacións meteorolóxicas, unha delas na Universidade de Santiago de Compostela, que enviaban as medidas recollidas á Junta General de Estadística del Reino e máis tarde ao Observatorio de Madrid. Non será ata 1887, coa creación do Instituto Central Meteorológico, cando esta disciplina en España teña como obxectivo a predición do tempo.

\section{MEDIDAS METEOROLÓXICAS REALIZADAS NA CÁTEDRA DE FÍSICA EXPERIMENTAL}

A Universidade de Santiago de Compostela amosou a finais do século XVIII certo interese pola astronomía e meteoroloxía. Así, no proxecto de construción dun novo edificio para a Universidade presentado por Ferro Caveiro en 1783 contemplábase a existencia dun observatorio astronómico e meteorolóxico na terraza. Non foi ata 1848 cando foi posible dispor dun observatorio de carácter meteorolóxico ${ }^{23}$ e en 1943 dun astronómico.

Domingo Fontán foi docente na cátedra de Física Experimental no curso académico 1818/1819. Aínda que gañara a cátedra de Matemáticas meses antes,

\footnotetext{
${ }^{20}$ Sobre a historia da meteoroloxía en España pode verse a monografía Meteorología, ideología e identidad en la España Contemporánea, escrita por Aitor Anduaga Egaña.

${ }^{21}$ Pódense ver estes rexistros no repositorio Arcimís da Agencia Estatal de Meteorología.

${ }^{22}$ Como exemplo, o médico viveirense Nicolás Taboada Leal recolleu distintos rexistros meteorolóxicos en 1829 para a realización dunha topografía médica de Vigo.

${ }^{23}$ Díaz-Fierros Viqueira (coord.), Historia da meteoroloxía..., páx. 31.
} 
non puido impartir no curso citado a materia de Matemáticas Sublimes, debido a que por Real Orde do 14 de setembro de 1818 restableceuse o plan de estudos de 1772 fronte o vixente de 1808. Na cátedra de Física Experimental, Fontán tivo como alumnos a Ramón Sancho Gutiérrez e a Benito Ángel Sotelo Ribas (Santiago de Compostela 1796-Santiago de Compostela 1874), que destacaría ao longo da súa traxectoria como docente en matemáticas e física. Como catedrático desta última disciplina no Instituto de Segundo Ensino da Coruña, dirixiu o seu observatorio meteorolóxico dende 1863 ata 1871, aínda que Sotelo xa fixera observacións meteorolóxicas con anterioridade de xeito non oficial dende a cátedra de Matemáticas do Real Consulado da Coruña ${ }^{24}$.

Respecto aos instrumentos cos que contaba a cátedra de Física Experimental, o Claustro do 18 de abril de $1816^{25}$ acordou que os catedráticos de Matemáticas e de Física Experimental emitiran un informe sobre os instrumentos que eran máis necesarios para o gabinete e o seu custo ${ }^{26}$.

No informe considerouse de primeira necesidade a adquisición de tres barómetros ${ }^{27}$ e dous termómetros ${ }^{28}$ de Fortin ${ }^{29}$ e unha escopeta de vento, instrumentos de óptica, ademais dunha máquina pneumática de indución.

O Claustro aprobou mercar o instrumental o 9 de xullo de 1816, creándose unha comisión formada por Domingo Fontán, Luis Pose Varela e Manuel García Lugín, aprobándose unha dotación de 17187 reais e 16 maravedíes para tal fin.

Máis tarde, coñecido que José Rodríguez González atopábase en París en 1817, encargouse a este a adquisición de instrumentos para a cátedra de Física Experimental. A relación de instrumentos adquiridos apareceron na Gaceta de Madrid do 4 de xuño de $1818^{30}$. Polo seu valor histórico citaremos a relación de aparellos chegados dende París segundo a relación dada por Domingo Fontán:

\section{Un círculo repetidor de Bordá de 17 1/2 pulgadas de diámetro cons- truido por Gambey, con toda la perfeccion que exigen sus usos bien}

\footnotetext{
24 José Ángel Docobo DurÁntez, Benito Ángel Dionisio Sotelo y Rivas [en liña], dispoñible en $<$ http:// culturagalega.gal/albumdaciencia/detalle.php?id=503> [Consulta: 01/02/2020].

${ }^{25}$ Con anterioridade, en novembro de 1813, Gonzalo Berena e Domingo Fontán dirixíronse ao alcalde de Santiago no que amosaban a necesidade de adquirir instrumentos para o ensino das ciencias naturais e exactas.

${ }^{26}$ Rafael Sisto Edreira e María Luisa Losada SAnMartín, Historia da Física na Universidade de Santiago de Compostela, Santiago de Compostela, Servizo de Publicacións e Intercambio Científico da Universidade de Santiago de Compostela, 2009, páx. 31.

${ }^{27}$ Instrumento que mide a presión atmosférica inventado por Torricelli no século XVII.

28 Instrumento que mide a temperatura do aire cuxa invención se atribúe a Galileo Galilei.

${ }^{29}$ Jean-Nicolas Fortin foi un afamado construtor francés de instrumentos científicos.

30 César CAMARgo SÁnchez, El curriculum de un cientifico [en liña], dispoñible en $<$ https://cuadernosdedomingofontan.com/2018/09/23/curriculum-de-un-cientifico/> [Consulta: 23/11/2019].
} 
conocidos: un excelente nivel con su anteojo y montura: un péndulo de segundos construido por Breguet, cuya marcha fue verificada: un metro en cobre subdividido en milimetros por Fortin: una soberbia máquina neumática con todos los aparatos que requieren sus numerosas é importantes aplicaciones, por el mismo: una máquina eléctrica con disco azul de 32 pulgadas de diámetro: dos conductores montados sobre su mesa y taburete aislador por el artista Dumotier. Los demas aparatos son los siguientes: tres botellas de Leide: aparato para la analisis de la botella de Leide: un excitador simple con charnela: dos cuadros mágicos de Franklin: un juego eléctrico de tres campanas: el signo eléctrico: un electróforo completo de 15 pulgadas de diámetro: un soplete y polvos para ambos fluidos: dos conductores para ser suspendidos en la base con cordones de seda: conductor de corchete para alargarse á arbitrio: tres conductores sencillos: cadena y cordoncillo de metal: tubo chispeador: tornasol con su punta: batería eléctrica de nueve frascos: electrómetro con cuadrante graduado en marfil: otro electrómetro con botella: un excitador con dos mangos de cristal: el excitador universal para la fusion de los metales: prensa para la fusion del oro: la decoupure de Franklin: el segundo taburete aislador; dos cilindros de lacre para la electricidad: dos globos ó grandes esferas de cristal guarnecidas de llaves y demas artículos para la aurora boreal y tambien para el peso de los gases; y finalmente amalgama para los usos eléctricos: una excelente balanza hidrostática con asideros para un juego doble de platillos: juego de pesas de 500 gramas con sus centígramas: vegiga con llave y ajustes metálicos para los gases: el aparato de la congelacion en el vacio: un excelente eudiómetro de Volta con dos tubos graduados, el uno de encaje y de diferente diámetro: un juego doble de grandes barras magnéticas: otro juego sencillo de agujas magnéticas con sus apoyos para montarlas: dos prismas montados en cobre, y el uno con círculo graduado: otro prisma acromático de tres vidrios igualmente montados: un poliprisma: tres lentes grandes y diferentes montadas todas: lente microscópico. Artículos vario de flint-glass por el artista Cauchoix; á saber, un prisma cónico en flint-glass ingles, cuyo ángulo refractante es el mayor posible, montado en pie de cobre: un prisma acromático de tres vidrios montado en su pie: un prisma en flint-glass frances de Mr. d'Ontigues de tres caras, cuyo ángulo refractante es el mayor posible: otro de $60^{\circ}$ montado en cobre con su pie: otro prisma en flint-glass frances, cuyo ángulo es recto, tambien montado: el tubo graduado de Mariotte para la compresion de los líquidos y otras aplicaciones: dos termómetros, el uno con regla de cristal por Fortin. 
$\mathrm{O}$ feito de que nesta relación non se atope ningún barómetro, fainos pensar que polo menos un destes aparellos foi adquirido anteriormente ao envío de instrumentos relatado o 4 de xuño, e aínda que por esas datas remítese a Rodríguez máis capital para o envío dunha nova remesa de aparellos, estes serían enviados á Universidade o 15 de abril de 1819 dende París, é dicir nunha data posterior á realización das medidas meteorolóxicas efectuadas por Fontán dende a cátedra de Física Experimental entre decembro de 1818 e marzo de 1819. Na Fundación Domingo Fontán consérvanse estas medidas que inclúen o estado da atmosfera e valores de temperatura e de presión tanto pola mañá como pola tarde. Aínda que algúns dos datos perdéronse polo estado de conservación dos documentos, cremos importante incluír aquí, polo seu valor histórico, as medicións de temperatura e de presión realizadas na cátedra rexentada por Fontán.

Táboa 1: Medidas meteorolóxicas efectuadas en decembro de 1818.

\begin{tabular}{|c|c|c|c|c|c|c|}
\hline Día & $\begin{array}{c}\text { T. } \\
\text { mañá }^{31}\end{array}$ & T. $^{\text {a } \text { tarde }^{32}}$ & $\begin{array}{c}\text { Presión mañá } \\
\left(\text { polgadas }^{33} \text { ) }\right.\end{array}$ & Liñas & $\begin{array}{c}\text { Presión } \\
\text { tarde } \\
\text { (polgadas) }\end{array}$ & Liñas \\
\hline 1 & 12 & 11,8 & 27 & 4,25 & 27 & 4,58 \\
\hline 2 & 9,5 & 12,5 & 27 & 5,58 & 27 & 5,25 \\
\hline 3 & 11 & 11,75 & 27 & 1,58 & 26 & 11,5 \\
\hline 4 & 10 & 11 & 26 & 10,67 & 26 & 11,5 \\
\hline 5 & 8 & 9,5 & 27 & 1 & 26 & 11,75 \\
\hline 6 & 10,5 & 11 & 27 & 0 & 26 & 11,58 \\
\hline 7 & 12,5 & 12,5 & 26 & 11,5 & 26 & 11,33 \\
\hline 8 & 11,87 & 11,87 & 27 & 1,25 & 27 & 1,25 \\
\hline 9 & 12 & 13 & 27 & 1,5 & 27 & 1,25 \\
\hline 10 & 12 & 12 & 27 & 0,5 & 26 & 11,73 \\
\hline 11 & 12 & 12 & 26 & 11,63 & 26 & 10,63 \\
\hline 12 & 9,5 & 12,5 & 26 & 11,63 & 27 & 0,25 \\
\hline 13 & 9,5 & & 27 & 1,57 & 27 & 2,30 \\
\hline 14 & 7,5 & 10,5 & 27 & 3,5 & 27 & 3,5 \\
\hline 15 & 8 & 13 & 27 & 3,75 & 27 & 4 \\
\hline
\end{tabular}

${ }^{31}$ T. ${ }^{a}$ mañá: Temperatura medida pola mañá.

${ }^{32} \mathrm{~T}^{\mathrm{a}}$ tarde: Temperatura medida pola tarde.

${ }^{33}$ Unidade de medida empregada entón en distintos países con distintas equivalencias. Débense entender ao longo deste artigo como polgadas francesas. 


\begin{tabular}{|c|c|c|c|c|c|c|}
\hline Día & $\begin{array}{c}\mathrm{T} .^{\mathrm{a}} \\
\text { mañá }^{31}\end{array}$ & T. ${ }^{\mathrm{a}} \operatorname{tarde}^{32}$ & $\begin{array}{c}\text { Presión mañá } \\
\left(\text { polgadas }^{33}\right)\end{array}$ & Liñas & $\begin{array}{c}\text { Presión } \\
\text { tarde } \\
\text { (polgadas) }\end{array}$ & Liñas \\
\hline 16 & 8,5 & 10 & 27 & 2,67 & 27 & 3,33 \\
\hline 17 & 8 & 9,5 & 27 & 3,33 & 27 & 2,33 \\
\hline 18 & 9 & 10 & 27 & 4 & 27 & 5,25 \\
\hline 19 & 9 & 10 & 27 & 6,5 & 27 & 3,25 \\
\hline 20 & 6,5 & 8 & 27 & 6,5 & 27 & 6,5 \\
\hline 21 & 1 & 8 & 27 & 6,25 & 27 & 5,75 \\
\hline 22 & 3 & 8 & 27 & 6,25 & 27 & 6,08 \\
\hline 23 & 4 & 7 & 27 & 6,33 & 27 & 6,25 \\
\hline 24 & 4 & 7 & 27 & 6,33 & 27 & 6,25 \\
\hline 25 & -1 & 7 & 27 & 5,42 & 27 & 4 \\
\hline 26 & 7 & 8 & 27 & 2,25 & 27 & 2 \\
\hline 27 & 6 & 8 & 27 & 2,17 & 27 & 2,33 \\
\hline 28 & 6 & 8 & 27 & 4,5 & 27 & 5 \\
\hline 29 & 6 & 7 & 27 & 5,33 & 27 & 4,17 \\
\hline 30 & 6,5 & 9 & 27 & 5,42 & 27 & 6,08 \\
\hline 31 & 6,33 & 9,33 & 27 & 5,75 & 27 & 5,42 \\
\hline
\end{tabular}

Comentarios:

- A maioría dos valores de temperatura que aparecen rexistrados son números enteiros e, nalgunhas ocasións, con parte decimal que na maioría dos casos só teñen unha cifra equivalente a medio grao. Chama a atención por non seguir as regras anteriores as temperaturas dos días $1(11,8)$ e do 3 pola tarde $(11,75)$, e as dos días $8(11,87)$ e $31(6,33)$ que ademais, agás a do día 1 , teñen dúas cifras decimais. A temperatura do día 13 pola tarde é ilexible.

- Dado que os valores de liñas de presión están indicados cun número natural máis dous decimais correspondentes a unha fracción con numerador entre 0 e 11 e denominador 12, parece que existe algún erro nas presións do día 10 pola tarde (debería ser 11,75 en lugar de 11,73), as do día 11 tanto de mañá como de tarde e do 12 pola mañá (debería ser 11,67 en lugar de 11,63) e do día 13 pola tarde (debería ser 2,33 en lugar de 2,30). 
Táboa 2: Medidas meteorolóxicas efectuadas en xaneiro de 1819.

\begin{tabular}{|c|c|c|c|c|c|c|}
\hline Día & T. ${ }^{a}$ mañá & T. ${ }^{\mathrm{a}}$ tarde & $\begin{array}{c}\text { Presión mañá } \\
\text { (polgadas) }\end{array}$ & Liñas & $\begin{array}{l}\text { Presión tarde } \\
\text { (polgadas) }\end{array}$ & Liñas \\
\hline 1 & 1,5 & 8 & 27 & 6,33 & 27 & 5,08 \\
\hline 2 & 6 & 8,5 & 27 & 6,25 & 27 & 5,67 \\
\hline 3 & 9 & 9 & 27 & 6,33 & 27 & 6,17 \\
\hline 4 & 9 & 10 & 27 & 5,5 & 27 & 5 \\
\hline 5 & 9 & 10 & 27 & 4,08 & 27 & 4 \\
\hline 6 & 7 & 10 & 27 & 4,25 & 27 & 5,08 \\
\hline 7 & 10 & 11 & 27 & 4,75 & 27 & 5,25 \\
\hline 8 & 10 & 11,67 & 27 & 4,17 & 27 & 4,25 \\
\hline 9 & 12 & 12,5 & 27 & 5,17 & 27 & 6,17 \\
\hline 10 & 12 & 13 & 27 & 5,5 & 27 & 9 \\
\hline 11 & 7 & 12 & 27 & 8,67 & 27 & 8 \\
\hline 12 & 10 & 12 & 27 & 6,58 & 27 & 4,25 \\
\hline 13 & 9,5 & 12 & 27 & 6,58 & 27 & 6,42 \\
\hline 14 & 7 & 12 & 27 & 8,5 & 27 & 9 \\
\hline 15 & 11 & 12,5 & 27 & 9 & 27 & 9,42 \\
\hline 16 & 7 & 14 & 27 & 9 & 27 & 8,58 \\
\hline 17 & 6 & 13 & 27 & 7 & 27 & 6,5 \\
\hline 18 & 7 & 11,5 & 27 & 6,17 & 27 & 6,17 \\
\hline 19 & 2 & 11 & 27 & 5,67 & 27 & 5,42 \\
\hline 20 & 7 & 12 & 27 & 5,5 & 27 & 5,67 \\
\hline 21 & 8 & 12 & 27 & 5,25 & 27 & 5,25 \\
\hline 22 & 11 & 12 & 27 & 3,5 & 27 & 3,5 \\
\hline 23 & 11 & 11,5 & 27 & 1,75 & 27 & 1,75 \\
\hline 24 & 10 & 11 & 27 & 0,67 & 27 & 2 \\
\hline 25 & 10 & 11 & 27 & 0,42 & 27 & 0,42 \\
\hline 26 & 7 & 6 & 26 & 10,5 & 26 & 10,5 \\
\hline 27 & 2 & 10 & 26 & 10,5 & 26 & 9,42 \\
\hline 28 & 6 & 11 & 26 & 10,58 & 26 & 10,58 \\
\hline 29 & 6 & 11 & 26 & 11,5 & 26 & 11,5 \\
\hline 30 & 8 & 10 & 26 & 10 & 26 & 10,67 \\
\hline 31 & 7 & 9 & 26 & 0,5 & 26 & 0,5 \\
\hline
\end{tabular}




\section{Comentarios:}

- A maioría dos valores de temperatura que aparecen rexistrados son números naturais e nalgunhas ocasións mídense fraccións de medio grao. Chama a atención a temperatura do día 8 de xaneiro de 1819 pola tarde $(11,67)$ por ter dous decimais. Tamén sorprende o valor anormalmente baixo da presión obtida o 31 de xaneiro (podería tratarse de 27 polgadas en lugar de 26).

Táboa 3: Medidas meteorolóxicas efectuadas en febreiro de 1819.

\begin{tabular}{|c|c|c|c|c|c|c|c|c|}
\hline Día & T. $^{\text {a }}$ mañá & T. $^{\text {a } \text { tarde }}$ & $\begin{array}{c}\text { Presión } \\
\text { mañá } \\
\text { (polgadas) }\end{array}$ & Liñas & Doc. $^{34}$ & $\begin{array}{c}\text { Presión } \\
\text { tarde } \\
\text { (polgadas) }\end{array}$ & Liñas & Doc. \\
\hline 1 & 6 & 9 & 26 & 11 & 2 & 26 & 9 & 7 \\
\hline 2 & 8,5 & 10 & 26 & 10 & 7 & 27 & 0 & 6 \\
\hline 3 & 4,5 & 9 & 27 & 2 & 8 & 27 & 3 & 3 \\
\hline 4 & 10 & 10 & 27 & 5 & 2 & 27 & 5 & 6 \\
\hline 5 & 8 & 10 & 27 & 5 & 8 & 27 & 5 & 8 \\
\hline 6 & 11,5 & 12,5 & 27 & 5 & 7 & 27 & 5 & 3 \\
\hline 7 & 11,5 & 12,5 & 27 & 4 & 6 & 27 & 5 & 6 \\
\hline 8 & 8 & 12,5 & 27 & 5 & 3 & 27 & 5 & 3 \\
\hline 9 & 8 & 12,5 & 27 & 5 & 8 & 27 & 5 & 8 \\
\hline 10 & 11 & 12,5 & 27 & 6 & 8 & 27 & 6 & 1 \\
\hline 11 & 10 & 14 & 27 & 7 & 2 & 27 & 6 & 9 \\
\hline 12 & 9 & 13 & 27 & 6 & 7 & 27 & 6 & 3 \\
\hline 13 & 9 & $131 / 3$ & 27 & 5 & 6 & 27 & 5 & 6 \\
\hline 14 & 12,5 & 15 & 27 & 5 & 4 & 27 & 4 & 0 \\
\hline 15 & 12 & 14 & 27 & 4 & 4 & 27 & 3 & 1 \\
\hline 16 & 13 & 13 & 27 & 3 & 5 & 27 & 3 & 5 \\
\hline 17 & 13 & 13 & 27 & 3 & 4 & 27 & 3 & 6 \\
\hline 18 & 12,5 & 13 & 27 & 3 & 5 & 27 & 2 & 7 \\
\hline 19 & 12 & 11 & 27 & 3 & 2 & 27 & 4 & 4 \\
\hline 20 & 12 & 13 & 27 & 3 & 9 & 27 & 4 & 4 \\
\hline 21 & 12,5 & 13 & 27 & 5 & 8 & 27 & 5 & 8 \\
\hline 22 & 8,5 & 13 & 27 & 6 & 6 & 27 & 6 & 9 \\
\hline
\end{tabular}

34 Doc.: Doceava. 


\begin{tabular}{|c|c|c|c|c|c|c|c|c|}
\hline Día & T. ${ }^{\text {a mañá }}$ & T. $^{\text {a }}$ tarde & $\begin{array}{c}\text { Presión } \\
\text { mañá } \\
\text { (polgadas) }\end{array}$ & Liñas & Doc. $^{34}$ & $\begin{array}{c}\text { Presión } \\
\text { tarde } \\
\text { (polgadas) }\end{array}$ & Liñas & Doc. \\
\hline 23 & 10 & 12 & 27 & 6 & 9 & 27 & 6 & 0 \\
\hline 24 & 10 & 11 & 27 & 5 & 8 & 27 & 4 & 9 \\
\hline 25 & 12 & 12 & 27 & 4 & 3 & 27 & 4 & 3 \\
\hline 26 & 8 & 11 & 27 & 4 & 9 & 27 & 4 & 8 \\
\hline 27 & 10 & 11 & 27 & 0 & 8 & 26 & 11 & 8 \\
\hline 28 & 8 & 11 & 26 & 11 & 8 & 26 & 11 & 0 \\
\hline
\end{tabular}

Comentarios:

- A maioría dos valores de temperatura que aparecen rexistrados son números naturais e nalgunhas ocasións mídense fraccións de medio grao. Chama a atención a temperatura do día 13 de febreiro de 1819 pola tarde (13 e unha fracción dun terzo) que non segue as regras anteriores.

- Fontán fai un cambio na expresión das liñas de polgada. En decembro de 1818 e xaneiro de 1819 empregou unha notación decimal. Neste mes de febreiro e no de marzo en lugar de expresar as liñas con dous díxitos decimais, separa en dúas columnas independentes o número enteiro de liñas e o numerador correspondente á fracción de liña (cuxo denominador é 12). En ambas as dúas columnas, polo tanto, expresa un número comprendido entre 0 e 11 , dado que unha polgada equivale a 12 liñas.

Táboa 4: Medidas meteorolóxicas efectuadas en marzo de 1819.

\begin{tabular}{|c|c|c|c|c|c|c|c|c|}
\hline Día & T. ${ }^{\text {a }}$ mañá & $\begin{array}{c}\mathrm{T}^{\mathrm{a}} \\
\text { tarde }\end{array}$ & $\begin{array}{c}\text { Presión } \\
\text { mañá } \\
\text { (polgadas) }\end{array}$ & Liñas & Doc. & $\begin{array}{c}\text { Presión } \\
\text { tarde } \\
\text { (polgadas) }\end{array}$ & Liñas & Doc. \\
\hline 1 & 8 & 11 & 26 & 9 & 0 & 26 & 9 & 4 \\
\hline 2 & 10 & 11 & 26 & 10 & 8 & 26 & 11 & 1 \\
\hline 3 & 8 & 8 & 26 & 9 & 4 & 26 & 7 & 9 \\
\hline 4 & 6 & 7 & 26 & 8 & 4 & 26 & 10 & 8 \\
\hline 5 & 4 & 8 & 27 & 10 & 7 & 27 & 11 & 3 \\
\hline 6 & 8 & 10 & 27 & 0 & 0 & 27 & 0 & 2 \\
\hline 7 & 4 & 8 & 27 & 0 & 0 & 27 & 0 & 0 \\
\hline 8 & 6 & 10 & 27 & 0 & 1 & 27 & 1 & 1 \\
\hline 9 & 7 & 12 & 27 & 1 & 2 & 27 & 1 & 2 \\
\hline
\end{tabular}




\begin{tabular}{|c|c|c|c|c|c|c|c|c|}
\hline Día & T. $^{\text {a }}$ manáa & $\begin{array}{c}\text { T. }^{\text {a }} \\
\text { tarde }\end{array}$ & $\begin{array}{c}\text { Presión } \\
\text { mañá } \\
\text { (polgadas) }\end{array}$ & Liñas & Doc. & $\begin{array}{c}\text { Presión } \\
\text { tarde } \\
\text { (polgadas) }\end{array}$ & Liñas & Doc. \\
\hline 10 & 8 & 13 & 27 & 2 & 0 & 27 & 3 & 0 \\
\hline 11 & 8 & 14 & 27 & 3 & 8 & 27 & 3 & 8 \\
\hline 12 & 10 & 16 & 27 & 3 & 8 & 27 & 4 & 2 \\
\hline 13 & 10 & 16 & 27 & 4 & 4 & 27 & 5 & 0 \\
\hline 14 & 13 & 18 & 27 & 5 & 3 & 27 & 6 & 4 \\
\hline 15 & 13 & 17 & 27 & 5 & 6 & 27 & 6 & 2 \\
\hline 16 & 13 & 17 & 27 & 6 & 8 & 27 & 6 & 10 \\
\hline 17 & 13 & 18 & 27 & 7 & 0 & 27 & 6 & 8 \\
\hline 18 & 15 & 17 & 27 & 6 & 3 & 27 & 5 & 10 \\
\hline 19 & 13 & 15 & 27 & 5 & 4 & 27 & 5 & 0 \\
\hline 20 & 14 & 15 & 27 & 4 & 2 & 27 & 4 & 2 \\
\hline 21 & 14 & 15 & 27 & 3 & 4 & 27 & 3 & 4 \\
\hline 22 & 15 & 14 & 27 & 2 & 8 & 27 & 2 & 3 \\
\hline 23 & 13 & 12 & 27 & 3 & 1 & 27 & 2 & 9 \\
\hline 24 & 13 & 14 & 27 & 4 & 1 & 27 & 4 & 0 \\
\hline 25 & 14 & 14 & 27 & 4 & 1 & 27 & 5 & 4 \\
\hline 26 & 14 & 14 & 27 & 4 & 1 & 27 & 5 & 5 \\
\hline 27 & 13 & 16 & 27 & 5 & 27 & 27 & 4 & 8 \\
\hline 28 & 14 & 15 & 27 & 4 & 5 & 27 & 4 & 7 \\
\hline 29 & 15 & 16 & 27 & 5 & 6 & 27 & 5 & 2 \\
\hline 30 & 11 & 16 & 27 & 6 & 4 & 27 & 6 & 6 \\
\hline 31 & 11 & 16 & 27 & 5 & 6 & 27 & 5 & 6 \\
\hline
\end{tabular}

Comentarios:

- Na táboa amosada anteriormente escribimos só o numerador da fracción indicada por Fontán, entendendo que dito numerador ten que dividirse entre 12 para obter os valores correctos.

No Congreso do Comité Meteorolóxico Internacional celebrado en Roma en 1879 acordouse establecer unhas táboas ${ }^{35}$ para as equivalencias entre as escalas

${ }^{35}$ Ditas táboas foron recollidas nas Tables Météorologiques Internationales que foron impresas en París en 1890 . 
métricas e as antigas medidas francesas e inglesas. Así establecéronse as seguintes equivalencias para as medidas francesas:

Táboa 5: Equivalencias de medidas.

\begin{tabular}{|c|c|}
\hline $\begin{array}{c}\text { Antigas medidas francesas (a } 13^{\circ} \text { Réau- } \\
\text { mur }^{36} \text { ) }\end{array}$ & Medidas métricas (a $0^{\circ}$ centígrados) \\
\hline 1 polgada $=12$ liñas & $27,069953 \mathrm{~mm}$ \\
\hline 1 liña & $2,255829 \mathrm{~mm}$ \\
\hline
\end{tabular}

Tendo en conta esta última táboa, formamos o seguinte resumo. Respecto a presión indicaremos os valores aproximados tanto mínimos e máximos en milímetros, independentemente de que a medida se realizase pola mañá ou pola tarde e desbotamos a medida do 31 de xaneiro por ser anormalmente baixa. Respecto á temperatura, teremos en conta se a medida se realizou ben de mañá ou de tarde.

Táboa 6: Resumo de medidas realizadas na cátedra de Física Experimental (decembro de 1818 - marzo de 1819).

\begin{tabular}{|c|c|c|c|c|c|c|}
\hline 37 & $\begin{array}{l}\text { T. }{ }^{a} \text { mín. } \\
\text { mañá }\end{array}$ & $\begin{array}{l}\text { T. }{ }^{\mathrm{a}} \text { máx. } \\
\text { mañá }\end{array}$ & $\begin{array}{c}\text { T. a mín. } \\
\text { tarde }\end{array}$ & $\begin{array}{c}\text { T. }{ }^{\mathrm{a}} \text { máx. } \\
\text { tarde }\end{array}$ & P. mín. & P. máx. \\
\hline Dec. 18 & -1 & 12,5 & 7 & 13 & 727,79 & 745,55 \\
\hline Xan. 19 & 1,5 & 12 & 6 & 14 & 725,06 & 752,13 \\
\hline Feb. 19 & 4,5 & 13 & 9 & 15 & 725,43 & 746,11 \\
\hline Mar. 19 & 4 & 15 & 7 & 18 & 721,30 & 756,26 \\
\hline
\end{tabular}

Pola correspondencia mantida entre Fontán e J. Castro, aspirante ao grao en bacharel en 1829, sabemos que nese ano se realizaron observacións meteorolóxicas dende a cátedra de Física Experimental que rexentaba Luis Pose Varela. Castro remitiu a Fontán varios rexistros termométricos e barométricos obtidos na Universidade.

\footnotetext{
${ }^{36}$ Para converter graos Réaumur $\left({ }^{\circ} \mathrm{Re}\right)$ a graos Celsius ou graos centígrados $\left({ }^{\circ} \mathrm{C}\right)$ emprégase a fórmula ${ }^{\circ} \mathrm{C}=1,25^{* 0} \mathrm{Re}$.

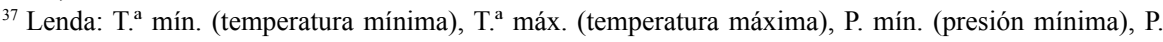
máx. (presión máxima).
} 


\section{MedidAs METEOROLÓXICAS REALIZADAS NA CORUÑA}

Segundo Camargo Sánchez, Fontán realizou medidas meteorolóxicas (barométricas e termométricas con descrición do tempo) na cidade da Coruña entre os meses de marzo e maio de 1822, concretamente na rúa das Damas, casa $3,2^{\circ}$ $\operatorname{andar}^{38}$.

\section{MEdicións METEOROLÓXICAS DE RAMÓN DE LA SAGRA}

Ramón Dionisio de la Sagra y Peris, alumno de Fontán no curso 1816/1817, foi nomeado para ocupar na Habana o cargo de catedrático de Historia Natural do Xardín Botánico desta cidade en 1823, na que xa estivera anteriormente entre 1820 e 1822 para tentar reorganizar a Factoría de Tabacos. Entre o seu nomeamento e a data de partida, de la Sagra elaborou un plan de traballo para a medición de distintas magnitudes (temperatura do aire e da superficie do océano, presión atmosférica...) durante a travesía entre A Coruña e a illa de Cuba, e reuniu os instrumentos necesarios para desenvolver o plan $^{39}$.

Respecto aos instrumentos o propio Ramón de la Sagra indica que Me costó sumo trabajo y actividad reunir los instrumentos necesarios para todas estas observaciones, e despois de indicar que non se podían pedir a un artista calquera, de la Sagra escribe que Mas afortunadamente dos jòvenes artistas de la ciudad de Santiago, à los cuales solo falta que las ciencias progresen en España para alcanzar la celebridad que merecen, desempeñaron mis encargos à toda mi satisfaccion. Referíase de la Sagra aos irmáns José e Domingo Lareo Quintela nados en Santiago de Compostela.

Conseguidos os instrumentos, Ramón de la Sagra reuniu os datos que precisaba na Biblioteca da Universidade de Santiago de Compostela, e comparou os termómetros cos de Fortin pertencentes tamén a esta institución. De José Rodríguez comenta de la Sagra que Este sabio compatriota reconoció en Santiago parte de mis instrumentos y me favoreció con advertencias de mucho provecho.

En maio de 1823, pouco antes de partir, dirixiuse cara A Coruña coa finalidade de realizar ensaios e colocar os instrumentos a bordo da fragata mercante $L a$ Activa na que faría a travesía. De la Sagra indica ao respecto que:

\footnotetext{
38 César CAmargo SÁnchez, El levantamiento de la carta geométrica de Galicia [en liña], dispoñible en $<$ https://cuadernosdedomingofontan.com/2017/10/21/el-levantamiento-de-la-carta-geometrica-degalicia/> [Consulta: 16/11/2019].

39 Ramón de la SAgra y PERIS, "Observaciones físicas hechas por D. Ramón Sagra en el Océano Atlántico, durante su viage de La Coruña a La Habana”, Memorias de la Sociedad Económica de la Habana, 46 (1823), páxs. 211-212.
} 
Durante mi permanencia en la Coruña, comuniqué el plan de mis trabajos à dos amigos, D. Domingo Fontan, profesor distinguido de las ciencias físicas y matemáticas, y D. José Garcìa, cuyo amor á la Historia natural iguala á la actividad con que la cultiva en el seno de la felicidad domèstica y del aprecio que le grangean las cualidades de su hermosa alma. Estos dos sugetos recomendables me franquearon el uno sus preciosos instrumentos y aparatos meteorológicos y físicos, construidos con todo esmero por Fortin y los mejores artistas de Europa para comparar con los mios, y el otro su bella coleccion de minerales, de la cual ha tenido la bondad de cederme la parte que podia sin destruirla.

Durante a súa viaxe que comezou o 25 de xuño de 1823, Ramón de la Sagra realizou as medicións planeadas e comparou os seus resultados cos obtidos por Alexander Von Humboldt na viaxe que realizou desde A Coruña cara Cuba o 5 de xuño do ano 1799. O éxito da misión de Ramón de la Sagra foi debida, en parte, grazas as achegas de Domingo Fontán no campo da meteoroloxía.

Posteriormente, de la Sagra realizaría medidas meteorolóxicas (pluviométricas) en Cuba durante 6 anos $^{40}$.

\section{Medicas meteorolóxicas Realizadas por Fontán na Casa de Ayala}

A partir do curso 1819/1820, Fontán impartiu a cátedra de Matemáticas na Universidade da que era titular en troques da de Física Experimental. Non coñecemos datos meteorolóxicos asociados a esta última cátedra neste curso polo que, ou ben os novos docentes non continuaron con esta labor ou ben de realizarse, non se conservan ou están desaparecidos.

Tras a restitución do absolutismo en 1823, Domingo Fontán foi desprovisto da súa cátedra na Universidade de Santiago de Compostela. Non por iso descoidou a súa faceta científica. Fontán realizou en Santiago de Compostela medidas meteorolóxicas no ano $1824^{41}$ na Casa de Ayala ${ }^{42}$ situada na rúa Picho de la Cerca n. ${ }^{\circ} 6$ (dita Casa estaría situada na actual rúa da Virxe da Cerca preto da Praza de Abastos compostelá).

\footnotetext{
40 DíAz-Fierros Viqueira (coord.), Historia da meteoroloxía..., páx. 33.

41 Nese ano, o 24 de abril, Fontán casou con Manuela Riva Gómez.

${ }^{42} \mathrm{Na}$ obra Galicia y el siglo XVIII: planos y dibujos de arquitectura y urbanismo (1701-1800) dirixida polo catedrático de Historia da Arte Alfredo Vigo Trasancos pode verse un proxecto de Monroy para a súa reconstrución datada do ano 1792.
} 
O nome desta Casa pode vir do administrador xeral de aduanas Nicolás de Ayala. Na biografía da súa dona, a escritora e editora María Francisca Isla y Losada, realizada por Carlos García Cortés, non consta que esta fose a vivenda do matrimonio Ayala-Isla aínda que si se fai referencia a unha casa desta rúa nunha modificación do testamento de Nicolás de Ayala ${ }^{43}$. García Cortés recolle que poucos días antes do seu falecemento, Ayala redactou o codicilo do 1 de outubro de 1774 ante o notario Pedro de la Peña onde indica que debido a haberse metido en obras en una casa del Picho de la Cerca, se le han agotado todos los caudales que poseía en efectivo.

Fontán utilizou os seguintes instrumentos: un barómetro de Fortin de gradación métrica, un termómetro centígrado, un higrómetro ${ }^{44}$, o anemómetro ${ }^{45}$ da Torre de Belvís e Chemineas, e un pluviómetro ${ }^{46}$ de 0,092 milímetros de cavidade.

Respecto ás medicións meteorolóxicas, ademais de recoller máis magnitudes das habituais como as de humidade e precipitación ${ }^{47}$, prodúcense novidades respecto ás medidas realizadas entre 1818 e 1819 na cátedra de Física Experimental da Universidade de Santiago. Así, respecto ás medidas de presión atmosférica empregou unha escala en milímetros fronte a escala en polgadas francesas utilizado na cátedra. Non cabe dúbida que Domingo Fontán estaba concienciado da importancia da adopción dun sistema internacional de medidas ${ }^{48}$ polos beneficios que supoñía a súa unificación e simplificación.

Ademais de obter medidas de máis magnitudes, Domingo Fontán elaborou unhas gráficas nas que se pode observar dunha ollada as variacións producidas ao longo do ano. Non era nada habitual na España daquela época realizar este tipo de traballos, aínda que si se facían nos países europeos máis avanzados.

De seguido vemos un resumo mensual formado a partir das medidas realizadas por Fontán ${ }^{49}$ nas que é preciso ter en conta que foron efectuadas unha vez ao día nas horas centrais.

\footnotetext{
${ }^{43}$ Carlos GArcía Cortés, María Francisca de Isla y Losada (1734-1808). Una conexión literaria en la Compostela de la Ilustración, Santiago de Compostela, Instituto de Estudios Gallegos Padre Sarmiento, CSIC, 2007 (Anejos de Cuadernos de Estudios Gallegos, 38).

${ }_{44}$ No manuscrito no que recolleu as medidas Fontán escribiu higrómetro de Laurenz centígrado.

${ }^{45}$ Posiblemente Fontán puido referirse a un catavento que indicaba a dirección de onde sopra o vento.

${ }^{46}$ No manuscrito no que recolleu as medidas Fontán escribiu pluviómetro ou hietómetro.

${ }^{47}$ En 1824, por exemplo, no Observatorio de San Fernando non se medían estas magnitudes e no Observatorio de Madrid non constan observaciones meteorolóxicas ese ano.

${ }^{48}$ Hoxe en día, a unidade do sistema internacional para a presión atmosférica é o Pascal.

49 Os datos completos que comprenden case todos os días do ano así como as gráficas consérvanse na Fundación Domingo Fontán.
} 
Táboa 7: Resumo das medidas meteorolóxicas efectuadas en 1824

\begin{tabular}{|c|c|c|c|c|c|c|c|}
\hline 50 & P. mín. & P. máx. & T. $^{\text {a }}$ mín. & T. ${ }^{\text {a máx. }}$ & H. mín & H. máx & Precip. \\
\hline Xan. & 73560 & 74890 & 6,5 & 11,5 & $\mathrm{x}$ & $\mathrm{x}$ & $\mathrm{x}$ \\
\hline Feb. & 71450 & 75300 & 7,8 & 14,4 & 79 & 94 & $\mathrm{x}$ \\
\hline Mar. & 73160 & 74965 & 9,5 & 17 & 65 & 92 & $\mathrm{x}$ \\
\hline Abr. & 72460 & 75040 & 11 & 16 & 65 & 90 & 0,094 \\
\hline Maio & 73370 & 74680 & 11,8 & 21 & 68 & 88 & 0,103 \\
\hline Xuñ. & 73320 & 74800 & 17 & 22,5 & 64 & 86 & 0,069 \\
\hline Xul. & 73735 & 74775 & 20 & 28 & 58 & 87 & 0,028 \\
\hline Ago. & 73970 & 74965 & 19,5 & 24 & 63 & 86 & 0,032 \\
\hline Set. & 72760 & 74540 & 16 & 23 & 77 & 92 & 0,114 \\
\hline Out. & 72900 & 75125 & 12,5 & 19 & 79 & 93 & 0,190 \\
\hline Nov. & 72530 & 75025 & 11,3 & 16,6 & 82 & 98 & 0,156 \\
\hline Dec. & 72670 & 75815 & 9,6 & 14 & 88 & 98 & 0,077 \\
\hline
\end{tabular}

\section{Comentario:}

- Fontán dá 5 díxitos para o valor da presión atmosférica. Dado que o valor da presión ao nivel do mar, a $0^{\circ}$ centígrados, nunha latitude de $45^{\circ}$, ten un valor de 760 milímetros de mercurio, inclinámonos a pensar que as dúas últimas cifras poden ser decimais.

Non semella que as medicións de 1824 e as súas gráficas asociadas teñan relación coa Carta Xeométrica de Galicia. Máis ben parece que fixo un traballo máis exhaustivo, tal e como se viña facendo noutros países europeos, posiblemente coa finalidade de mellorar a súa formación.

\section{MEDIDAS REALIZADAS AO ABEIRO DA CARTA XEOMÉTRICA DE GALICIA}

O traballo de elaboración da grande obra de Fontán, a Carta Xeométrica de Galicia, comezouna en 1817 despois de facer en novembro do ano anterior as primeiras observacións a modo de adestramento no Pazo de Sobrecarreira en Sigrás (Cambre) propiedade de Antonio Loriga y Reguera.

Fontán sabía que esta obra era fundamental para o desenvolvemento da economía e das comunicacións en Galicia e compaxinou esta tarefa coa docencia

\footnotetext{
${ }^{50}$ Lenda: P. mín (presión mínima), P. máx (presión máxima), T. ${ }^{a}$ mín. (temperatura mínima), T. máx. (temperatura máxima), H. mín (humidade mínima), H. máx (humidade máxima), Precip. (precipitación).
} 
na cátedra de Matemáticas da Universidade de Santiago de Compostela, e tamén con distintos postos que ocupou na administración. Estes postos, dos que indicamos tamén o ano do seu nomeamento, foron os de membro da xunta de repartimento de tributos en representación da comarca do Salnés (1818), e xa no Trienio Liberal como secretario da Deputación Provincial de Galicia (1820) e secretario da Deputación Provincial da Coruña $(1822)^{51}$.

Tamén foi requirido para distintas tarefas, como encargado da división xudicial e municipal de Galicia (1826) e como responsable do trazado das estradas que se abrirían na xeografía galega (1829).

En 1834, Fontán é nomeado individuo da comisión de rectificación de límites das provincias e arranxos de partidos xudiciais, e obtivo as cátedras de Xeometría Mecánica e Delineación Aplicada ás Artes no Conservatorio de Artes, así como a de Física, Mecánica e Delineación das Artes na Sociedade Económica de Amigos del País de Santiago de Compostela. Tamén neste ano redactou a "Memoria sobre la formación de los planos topográficos de las provincias y Carta General del Reino", que foi publicada en dúas partes nos números 14 e 15 da Revista Jurídica y Administrativa de Galicia.

Ata entón, todos os mapas de Galicia foran realizados con pouco rigor ${ }^{52}$. Concretamente o de Fontán foi o primeiro que empregou para esta tarefa o método científico (triangulación) que xa se viña usando noutros países europeos. Respecto ao Mapa de España non se comezou a utilizar este método ata mediados do século XIX publicándose a primeira folla (correspondente a Madrid) no ano 1875 .

Para a formación nun mapa é indispensable coñecer a latitude e a lonxitude xeográficas dun conxunto de pobos e lugares notables do territorio que se pretende modelar, o cal é un traballo longo e penoso. O método de triangulación consiste en cubrir un territorio mediante unha rede de triángulos e permite obter un mapa de gran precisión a partir do coñecemento da verdadeira distancia dun ou dous lados dun triángulo (bases) e a posición exacta dun dos vértices ou estacións, é dicir, determinando a latitude e lonxitude xeográficas, así como o acimut (o ángulo que forma o meridiano do lugar respecto aos vértices ou estacións inmediatas) coa maior precisión ${ }^{53}$.

\footnotetext{
${ }^{51}$ Para exercer estes últimos cargos, Fontán fixou a súa residencia na Coruña ata 1823, cidade na que tamén participaba na Sociedade Patriótica.

52 Non para todo o territorio, Vicente Tofiño empregou este método para cartografar as costas de Galicia a finais do século XVIII.

53 Iván FERnÁndez PÉRez, “O traballo do matemático Rodríguez sobre a formación do mapa de España e a súa influencia sobre a carta xeométrica de Galicia de Domingo Fontán”, Adra, 11 (2016), páx. 109.
} 
A este respecto, na Memoria para a formación do mapa de España de José Rodríguez González na que se baseou Fontán para a elaboración da Carta indícase que ${ }^{54}$ :

Los lados de estos triangulos seran las verdaderas distancias de unos objetos a otros, las quales pueden determinarse facilmente por el calculo; en conociendo uno ó dos de estos lados en medidas lineares, como varas ó toesas. Estos lados de un tamaño conocido por medidas tomadas sobre el terreno, que sirben para el calculo del largo de todos los mas que componen la serie de triangulos, se les denomina Bases.

Para determinar la latitud y longitud de los puntos, y objetos que sirven de vertice a los triangulos se hace preciso determinar de antemano la latitud y longitud de uno de estos vertices ó estaciones por medio de repetidas obserbaciones de las estrellas circumpolares, de los eclipses de los satelites de Jupiter, ocultaciones de estrellas por la luna y por los eclipses de esta.

Hecho esto se tiene por el calculo y con grande precisión la latitud y longitud de todos los mas objetos que componen el conjunto de triangulos y cuyas distancias son ya conocidas.

Mas para verificarse este calculo se hace indispensable determinar igualmente por medio del Sol ó del paso de las estrellas, el angulo que forman con el meridiano de la estacion de latitud conoci$d a$, el circulo vertical que pasa por esta y una de las estaciones o vertices ymediatos. Este angulo se llama el Azimuz de la segunda estacion visto de la primera.

Conocidos pues los lados de toda la serie de triangulos, la latitud y longitud del vertice de uno de estos, y el Azimuz del lado entre este vertice y qualquiera de los imediatos; se tienen todos los datos para calcular la latitud y longitud de las mas estaciones, su elevacion sobre el nivel del mar, la area de los triangulos y por consiguiente la area total del terreno, cuyo plano se quiere levantar.

Así, en 1820, Fontán mediu a base de Formarís obtendo despois das correccións oportunas unha distancia entre os dous extremos de 2294,54 metros (2744,8 varas españolas).

\footnotetext{
${ }^{54}$ Fundación Domingo Fontán, Memoria sobre las operaciones necesarias para la formación de un mapa general de España y de sus provincias en particular. Presentada a la Junta Suprema Central del reino y mandada formar por la misma, caixa 42, carpeta 5, apartado 7.
} 
En agosto e setembro de 1821 determinou as medidas de latitude e lonxitude xeográficas do vértice principal, a Torre do Reloxo da Catedral de Santiago de Compostela. O valor obtido da latitude foi de $42^{\circ} 52^{\prime} 33^{\prime}$ " Norte, para a que realizou máis de 144 observacións da estrela Polar, por outras 200 de Orión e pola altura meridiana do Sol. O valor obtido da lonxitude foi de $4^{\circ} 48^{\prime} 15^{\prime}$ ' respecto ao occidente de Madrid, deducido de varias observacións de inmersións do primeiro satélite de Xúpiter, segundo deixou escrito Sebastián Miñano y Bedoya no seu Diccionario Geográfico y Estadístico de España y Portugal publicado en 1827.

En setembro de 1828, Fontán xunto con Alejo Andrade Yáñez (1793-1844) que traballaba na estrada entre Santiago e Lugo, mediron unha segunda base no Corgo. A medida entre os dous extremos resultou 4995,392897 metros, que reducidos ao nivel do mar calcularon en 4994,878679 metros.

Ademais de ser un pioneiro no emprego do método de triangulación para a elaboración dun mapa de Galicia, Fontán empregou para isto o sistema métrico decimal $^{56}$, adiantándose ao seu uso oficial.

Para as medicións necesarias tanto nas bases coma nas estacións Fontán contou con instrumentos da súa propiedade como o teodolito Gambey ${ }^{57}$, un sextante de peto conservado no Museo de Pontevedra ${ }^{58}$, e un barómetro de Fortin ${ }^{59}$. Na Fundación Domingo Fontán consérvanse entre outros, unha alidada de pínulas con compás concéntrico e nivel de burbulla de aire e un barómetro de sifón Bunten fabricado en París. Este último era máis práctico respecto ao barómetro de cubeta de Fortin que usaba o seu irmán Andrés ${ }^{60}$ e que rachou en 1834, substituíndoo por un barómetro de Fortin construído polos irmáns Domingo e José Lareo.

Fontán empregou tamén as perchas ${ }^{61}$ para a medida das bases de Formarís e do Corgo que foron elaboradas polos irmáns Lareo, construtores tamén dunha prancheta circular ideada por Fontán, tal como se recolle no Tratado Elemental de Matemáticas escrito por José Mariano Vallejo Ortega.

Así, no tomo I desta obra na súa terceira edición de 1825, Vallejo indica que:

\footnotetext{
55 Nado en Monforte de Lemos. Foi arquitecto e enxeñeiro de camiños.

${ }^{56}$ Por Lei do 19 de xullo de 1849 aprobouse a posta en marcha deste sistema que entrou en vigor como uso obrigatorio en España o 1 de xuño do ano 1880.

57 Doado polas netas de Fontán, Enriqueta e Regina Fontán Medina, á Universidade de Santiago en 1964 e que figura exposto na Facultade de Xeografía e Historia.

58 Doado por Rosendo Fontán Riva, un dos fillos que tivo Fontán coa súa dona Manuela Riva, á Sociedade Arqueolóxica de Pontevedra en 1898.

59 Doado en 1873 polos seus fillos Félix e Rosendo aos doutores Antonio Casares Rodríguez e Acisclo Campano Alfageme para o instituto de segundo ensino de Santiago de Compostela.

${ }^{60}$ Andrés Fontán Rodríguez foi avogado dos reais consellos.

${ }^{61}$ Entendidas na súa acepción de listóns longos e delgados.
} 
A mi tránsito por la Coruña en Enero de 1824, tuve la satisfacción de conocer personalmente al Doctor Domingo Fontán, Catedrático de Matemáticas Sublimes de la Universidad de Santiago de Compostela, el cual me enseñó una plancheta circular inventada por él y construida en dicha ciudad de Santiago en 1820 por los inapreciables instrumentistas Don José y Don Domingo Lareo. La expresada plancheta es sin disputa mucho más exacta, cómoda y ventajosa que la creada generalmente, y como hace honor no solo al inventor y constructores, sino también a la Nación.

Tamén contou nalgunhas ocasións con instrumentos pertencentes á Universidade de Santiago como o metro de Fortin ou de particulares como o telescopio propiedade da Condesa de Maceda, Ramona Pardo de Figueroa Correa y Sarmiento, e que hoxe se conserva no Pazo de Fefináns en Cambados. Con este último instrumento, Fontán realizou en 1821 observacións dos planetas Xúpiter e Saturno ${ }^{62}$, complementarias ás que realizou para a obtención da lonxitude da Torre do Reloxo da catedral de Santiago de Compostela.

Para a elaboración da carta, coñécese que contou coa axuda en distintas etapas de José Dionisio Valladares Gómez ${ }^{63}$ (1787-1864) e Benito María Pla e Cancela $^{64}$ (1812-1874) que recoñeceron partes do territorio galego por encargo de Fontán. Tamén contou coa axuda dos xa citados Domingo e José Lareo Quintela, Alejo Andrade Yáñez e Benito Ángel Sotelo Ribas.

Entre a variedade de medidas necesarias para esta tarefa foi precisa a realización de medicións da temperatura e da presión atmosférica ${ }^{65}$.

As primeiras foron fundamentais para determinar coa máxima precisión a medición das bases, dado que as perchas empregadas sufrían dilatacións polo que era preciso corrixir as lonxitudes destas segundo a temperatura obtida no momento de realizar a medicións.

As segundas eran necesarias para determinar a altura da estación xeodésica. Nas horas convidas medíase a presión atmosférica tanto na estación como a nivel do mar. Estas últimas foron realizadas por Andrés, o irmán de Domingo Fontán, dende a vila de Noia.

\footnotetext{
${ }^{62}$ Iván FernÁndez PÉrez, "Notas sobre os inicios da Astronomía en Galicia: de Domingo Fontán a Ramón María Aller”, Descubrindo, 12 (2013), páx. 90.

${ }^{63}$ Nado na parroquia de Santa María de Groba en Silleda, formouse en Leis e ocupou distintos cargos públicos.

${ }^{64}$ Nado en Ferrol. Estudou Leis e tivo unha relevante participación política.

${ }^{65}$ Nos cadernos de campo conservados na Fundación Domingo Fontán poden verse numerosas medidas realizadas en Noia e nas distintas estacións, así como cálculos da altitude sobre o nivel do mar nestas últimas.
} 
Fontán triangulou primeiro a parte occidental de Galicia. Así en 1823 tiña este traballo moi avanzado ${ }^{66}$. Pouco puido avanzar nesta tarefa entre 1823 e 1826 debido a que foi perseguido polas súas ideas liberais. Unha vez que obtivo o perdón de Fernando VII en $1826^{67}$ puido continuar cos traballos de campo e rematou a triangulación occidental en 1828. En 1834 rematou a parte oriental e presentou a Carta Xeométrica ante a raíña gobernadora María Cristina de Borbón. Con todo, Domingo Fontán realizou máis medicións e cálculos e foi introducindo melloras no mapa ata 1845 , ano no que se imprimiu a Carta Xeométrica no obradoiro do gravador Bouffard e o impresor Lemercier en París.

O mapa de Fontán non foi superado en calidade ata a década dos 40 do pasado século XX na que se completaron as follas correspondentes a Galicia do Mapa Topográfico Nacional de escala 1:50000068.

Ademais da Carta Xeométrica de Galicia, Fontán é autor doutros mapas ${ }^{69}$. Entre eles podemos citar o "Plano de la Ría de Arosa", ou o "Plano del Pais adyacente a las tres rias de la Coruña, Betanzos y Ferrol llamado de las Mariñas" que apareceron no citado Diccionario Geográfico y Estadístico de España y Portugal de Sebastián Miñano.

\section{FontÁn NO OBSERVATORIO AsTRONÓMICO DE MADRID}

Fontán foi nomeado en 1835 director do Observatorio Astronómico de Madrid uns meses despois de presentar a Carta Xeométrica de Galicia. Tamén nese ano foi nomeado director da Escola Especial de Enxeñeiros Xeógrafos, e así mesmo se lle encargou a formación do Corpo de Enxeñeiros de Camiños, Minas e Montes. Un ano despois sería nomeado tamén membro da Comisión de Pesas e Medidas.

Polo que respecta ao Observatorio, cando José Rodríguez González abandonou a súa dirección en 1823 o estado era lamentable a pesar de que se iniciaran as obras para a súa remodelación. Peor estaba a situación cando entrou Fontán posto que ninguén mirara por ela dende entón.

Dende o punto de vista científico, neste período de tempo Fontán conseguiu, non sen esforzo, recuperar o instrumental existente, que naquel momento estaba

\footnotetext{
${ }^{66}$ Concluíra as actuais provincias da Coruña e de Pontevedra, agás o bispado de Tui, dos cinco partidos meridionais e dalgunhas comarcas do partido de Corcubión.

${ }^{67}$ Anteriormente fora sometido a xuízo en dúas ocasións ante a Junta de Purificación de Santiago.

${ }^{68}$ Gonzalo Méndez Martínez, Domingo Fontán, Santiago de Compostela, Dirección Xeral de Promoción Cultural, Xunta de Galicia, 2005, páx. 72.

69 Pode verse unha relación completa na tese de doutoramento de María del Carmen Álvarez Monterroso.
} 
depositado no Museo de Ciencias Naturais, entidade da que dependía o Observatorio naquela época.

Non foi posible por Fontán iniciar un plan de observacións astronómicas, pero si impartiu docencia, aínda que a un número reducido de persoas, e baixo a súa dirección modernizáronse as medicións meteorolóxicas nesta instalación.

Concretamente realizábanse medicións ás 9:00, ás 12:00, ás 16:00 e ás 22:00 de presión atmosférica (lectura do barómetro con escala en milímetros -antes facíase mediante a escala de polgadas e liñas francesas), de temperatura en graos centígrados (antes Réaumur) e de precipitacións en milímetros ${ }^{70}$.

Fontán contou para esta tarefa como axudante do Observatorio con Pedro María Delgado Sandino, quen se suicidou o 6 de xuño de 1839 dun disparo, segundo se indica en distintas publicacións da época. Naquel momento, Delgado era director interino ao estar ausente Fontán que se atopaba en París preparando o gravado da Carta Xeométrica de Galicia.

Fontán estivo á fronte do Observatorio compaxinando esta tarefa coa súa dedicación como Deputado en Cortes en distintas lexislaturas, ata o triunfo da revolución de 1840 que supuxo o exilio da raíña María Cristina de Borbón e o inicio da rexencia do xeneral Baldomero Espartero. O enxeñeiro Jerónimo del Campo relevaría a Fontán na dirección do Observatorio.

Como político, Fontán formou parte de diferentes comisións parlamentarias e interveu sobre temas moi diversos, de xeito relevante en asuntos relacionados coa organización do Estado, a Facenda estatal e o proxecto de Constitución ${ }^{71}$. Entre outros, debateu con Pascual Madoz Ibáñez, autor do Diccionario geográfico-estadístico-histórico de España y sus posesiones de Ultramar no que colaborou Fontán.

\section{ÚLTIMOS ANOS DA VIDA DE FONTÁN}

Tras a súa destitución na dirección do Observatorio de Madrid, Fontán continuou a súa actividade como Deputado en Cortes (elixido como tal nas eleccións de 1841 e 1843) e dedicouse tamén á administración da fábrica de papel de Castro de Lousame ${ }^{72}$ (labor que continuaron seus fillos Félix e Manuel).

\footnotetext{
70 José Mario Giménez de la CuAdra, "La Meteorología en el Observatorio Astronómico de Madrid", Doscientos años del Observatorio Astronómico de Madrid, Madrid, Asociación de Amigos del Observatorio Astronómico de Madrid, 1992, páx. 120.

71 Margarita Barral Martínez, Domingo Fontán Rodríguez [en liña], dispoñible en $<$ http://www.culturagalega.org/albumdaciencia/detalle.php?id=318> [Consulta: 01/02/2020].

${ }_{72}$ Tras recibir Domingo e o seu irmán Andrés a participación que tiña nesta empresa o seu tío Sebastián, estes mercaron o resto de participacións a outros socios quedando así co control da fábrica.
} 
En 1852 foille concedida polo Consejo de Instrucción Pública unha pensión de xubilación de 24000 reais anuais.

Colaborou no Diccionario enciclopédico de la lengua española (Madrid: Gaspar y Roig, 1853 y 1855) $)^{73}$ dirixido por Eduardo Chao Fernández, nado en Ribadavia en 1822.

Tamén publicou os seguintes traballos no semanario La Exposición Compostelana $^{74}$. Periódico semanal de intereses materiales, nos que amosaba as súas inquedanzas sobre o fomento da agricultura:

- “El fomento de la producción”. No n. 7 do 13 de xuño de 1858.

- “Sobre la utilización de los juncales". No n. 9 do 27 de xuño de 1858.

- "El saneamiento de la Limia y la Tierra Llana". No n. ${ }^{o} 11$ do 11 de xullo de 1858.

- "El poder público y el fomento de la producción". No n. ${ }^{\circ} 13$ do 23 de xullo de 1858.

Nese ano de 1858 foi tamén nomeado socio correspondente do Instituto Agrícola Catalán de San Isidro.

Escribe tamén o artigo "Ferro-Carril de Santiago a la Ría de Padrón", no número 19 do 10 de maio de 1860 da Revista Económica. Periódico agrícola, artístico y comercial publicada tamén baixo a dirección da Sociedad Económica de Amigos del País de Santiago de Compostela. Nesta institución, na que xa fora vicesecretario en 1814, desempeñou nesta etapa os cargos de arquiveirobibliotecario (nomeado en 1858), director (nomeado en 1860) e foi distinguido como socio de honra (1862).

Fontán traballou arreo con distintos informes, para a posta en marcha do camiño de ferro entre Santiago de Compostela e Carril, da vía Santiago-BetanzosFerrol, así como da vía polo que debería circular o ferrocarril central de Galicia. Respecto ao primeiro trazado, o 4 de xaneiro de 1861 as Cortes outorgáronlle a concesión a Domingo Fontán, Joaquín Caballero e Inocencio Vilardebó, liña que non puido ver rematada Fontán dado que foi inaugurada en 1873 despois de 11 anos de obras.

Dende o punto de vista científico, é de salientar o seu traballo realizado na observación da eclipse de Sol do 18 de xullo de 1860. Esta eclipse espertou un grande interese na comunidade científica pois foi a primeira vez na que se em-

\footnotetext{
73 Carmen Manso Porto, Domingo Fontán Rodríguez [en liña], dispoñible en $<$ http://dbe.rah.es/biografias/17619/domingo-fontan-rodriguez> [Consulta 08/02/2020].

${ }^{74}$ Estes traballos están tamén recollidos nun apéndice do libro Vida y obra de Domingo Fontán, escrito por Xosé Lois Vila Fariña.
} 
pregaron técnicas novidosas de espectroscopía, fotografía e polarimetría para o estudo do $\mathrm{Sol}^{75}$.

Os resultados das observacións realizadas por Fontán non foron publicados posiblemente pola dificultade detectada, nos días previos, de considerables retrasos entre un reloxo e un péndulo. Os datos sobre os axustes de ambos os dous instrumentos así como as medicións realizadas consérvanse na Fundación Domingo Fontán.

Polo seu valor histórico incluímos aquí o resultado das observacións realizadas por Fontán dos contactos desta eclipse, que en Galicia foi parcial ${ }^{76}$.

Táboa 8: Medidas efectuadas por Fontán da eclipse de Sol de 1860

\begin{tabular}{|c|c|c|}
\hline & Cronómetro & Péndulo \\
\hline $\begin{array}{l}\text { Mancha grande } \\
\text { (comezo da eclipse) }\end{array}$ & $1 \mathrm{~h} 10 \mathrm{~m} 4 \mathrm{~s}$ & $1 \mathrm{~h} 10 \mathrm{~m} \mathrm{5,171 \textrm {s }}$ \\
\hline Volveu a verse & $2 \mathrm{~h} 27 \mathrm{~m} 18 \mathrm{~s}$ & $2 \mathrm{~h} 27 \mathrm{~m} \mathrm{20,445 \textrm {s }}$ \\
\hline $\begin{array}{l}\text { Mancha superior } \\
\text { aparente }\end{array}$ & $1 \mathrm{~h} 53 \mathrm{~m} 34 \mathrm{~s}$ & $1 \mathrm{~h} 53 \mathrm{~m} \mathrm{35,893 \textrm {s }}$ \\
\hline Volveu a verse & $3 \mathrm{~h} 3 \mathrm{~m} 45 \mathrm{~s}$ & $3 \mathrm{~h} 3 \mathrm{~m} \mathrm{48,062 \textrm {s }}$ \\
\hline $\begin{array}{c}\text { Mancha case no diámetro } \\
\text { horizontal }\end{array}$ & $1 \mathrm{~h} 58 \mathrm{~m} 44 \mathrm{~s}$ & $1 \mathrm{~h} 55 \mathrm{~m} \mathrm{45,979 \textrm {s }}$ \\
\hline Volveu a verse & $3 \mathrm{~h} 9 \mathrm{~m} 5 \mathrm{~s}$ & $3 \mathrm{~h} 9 \mathrm{~m} 8,151 \mathrm{~s}$ \\
\hline Fin da eclipse & $3 \mathrm{~h} 21 \mathrm{~m} 50 \mathrm{~s}$ & $3 \mathrm{~h} 21 \mathrm{~m} \mathrm{53,304 \textrm {s }}$ \\
\hline
\end{tabular}

Tras unha prolífica vida, Fontán finou en Cuntis o 24 de outubro de 1866 . Foi soterrado no cemiterio de Santiago de Compostela, e dende 1988 os seus restos repousan no Panteón dos Galegos Ilustres en San Domingos de Bonaval.

Como distincións en vida foi recoñecido como académico correspondente da Real Academia de Historia (1826), membro da Société de Géographie de París (1838) e Cabaleiro da Orde de Carlos III (1848).

\footnotetext{
75 Manuel López Arroyo, "Los dos siglos de existencia del Observatorio Astronómico de Madrid", Doscientos años del Observatorio Astronómico de Madrid, Madrid, Asociación de Amigos del Observatorio Astronómico de Madrid, 1992, páxs. 10-11.

${ }^{76}$ Nunha franxa da Península entre o cantábrico e o levante a eclipse foi de carácter total.
} 


\section{CONCLUSIÓNS}

Fontán é coñecido como matemático, cartógrafo, político... A súa obra foi grande e prolífica. Preocupouse polas comunicacións de Galicia e do fomento da súa economía, valéndose da ciencia para acadar avances nestes eidos. Cultivou a ciencia aplicada, pero tamén realizou traballos de ciencia básica que non foron publicados no seu día.

No que respecta á meteoroloxía, as observacións realizadas dende a cátedra de Física Experimental entre 1818 e 1819 indican que este tipo de medicións xa se realizaban na Universidade de Santiago de Compostela moito antes do que se pensaba.

As observacións realizadas dende a Casa de Ayala en 1824 supuxeron un salto de calidade ao ampliar o número de magnitudes a medir, por realizar gráficas para estudar a súa evolución anual e por empregar unha unidade de medida universal para a presión atmosférica en lugar da medida en polgadas francesas que se utilizaba na época de xeito habitual.

É de salientar ademais que formou nesta disciplina a persoeiros como Ramón de la Sagra ou Benito Ángel Sotelo y Ribas que tamén cultivaron a meteoroloxía nalgún momento das súas traxectorias vitais, así como a súa labor esquecida no Observatorio Astronómico de Madrid no que modernizou as observacións coa utilización de escalas métricas confirmando o seu compromiso pola adopción dun sistema internacional de medidas en España.

Por outra banda, a exactitude da Carta Xeométrica de Galicia non se podería conseguir se as medicións realizadas, entre elas as correspondentes ás meteorolóxicas, non se efectuaran con rigor.

Todo isto dá boa proba do traballo serio realizado por Domingo Fontán nesta disciplina e, sen dúbida, merece tamén ser recoñecido como un gran especialista no eido da meteoroloxía en Galicia.

\section{BIBLIOGRAFÍA}

Álvarez Monterroso, María del Carmen, A parroquia galega a partir da "Carta Geométrica de Galicia”, tese de doutoramento, Universidade de Santiago de Compostela, 2015.

Anduaga Egaña, Aitor, Meteorología, ideología y sociedad en la España Contemporánea, Madrid, Consejo Superior de Investigaciones Científicas, Agencia Estatal de Meteorología, 2012.

Barral Martínez, Margarita, Domingo Fontán Rodríguez [en liña], dispoñible en $<$ http://www. culturagalega.org/albumdaciencia/detalle.php?id=318> [Consulta: 01/02/2020]. 
Camargo Sánchez, César, El curriculum de un científico [en liña], dispoñible en $<$ https:// cuadernosdedomingofontan.com/2018/09/23/curriculum-de-un-cientifico/> [Consulta: 23/11/2019].

Camargo Sánchez, César, El levantamiento de la carta geométrica de Galicia [en liña], dispoñible en $<$ https://cuadernosdedomingofontan.com/2017/10/21/el-levantamiento-de-lacarta-geometrica-de-galicia/> [Consulta: 16/11/2019].

Commité Météorologique International, Tables Météorologiques Internationales: publiées conformément a une décision du Congrès tens en Rome en 1879, Gauthier-Villars et fils, Paris, 1890.

D. Domingo Fontán y su Mapa de Galicia: en el primer centenario de su publicación, Santiago de Compostela, Instituto Padre Sarmiento de Estudios Gallegos, CSIC, 1946 (Anejos de Cuadernos de Estudios Gallegos, 1).

Díaz-Fierros Viqueira, Francisco (coord.), Historia da meteoroloxía e da climatoloxía en Galicia, Santiago de Compostela, Consello da Cultura Galega, 2008.

Diccionario Biográfico Español, Alejo Andrade Yáñez [en liña], dispoñible en $<$ http://dbe.rah. es/biografias/22649/alejo-andrade-yanez> [Consulta 08/02/2020].

Docobo Durántez, José Ángel, Benito Ángel Dionisio Sotelo y Rivas [en liña], dispoñible en $<$ http://culturagalega.gal/albumdaciencia/detalle.php?id=503> [Consulta: 01/02/2020].

Fernández Cortizo, Camilo, "Población rural, mundo urbano y migraciones", Historia de la Galicia Moderna: siglos XVI-XIX, Santiago de Compostela, Servizo de Publicacións e Intercambio Científico da Universidade de Santiago de Compostela, 2012, páxs. 39-94.

Fernández Pérez, Iván, "Notas sobre os inicios da Astronomía en Galicia: de Domingo Fontán a Ramón María Aller”, Descubrindo, 12 (2013), páxs. 89-106.

Fernández Pérez, Iván, “O traballo do matemático Rodríguez sobre a formación do mapa de España, e a súa influencia sobre a carta xeométrica de Galicia de Domingo Fontán”, Adra, 11 (2016), páxs. 105-116.

García Cortés, Carlos, María Francisca de Isla y Losada (1734-1808). Una conexión literaria en la Compostela de la Ilustración, Santiago de Compostela, Instituto de Estudios Gallegos Padre Sarmiento, CSIC, 2007 (Anejos de Cuadernos de Estudios Gallegos, 38).

Giménez de la Cuadra, José Mario, "La Meteorología en el Observatorio Astronómico de Madrid", Doscientos años del Observatorio Astronómico de Madrid, Madrid, Asociación de Amigos del Observatorio Astronómico de Madrid, 1992, páxs. 115-140.

González López, Emilio, Entre el Antiguo y el Nuevo Régimen: Absolutistas y Liberales. El reinado de Fernando VII en Galicia, Sada, Edicións do Castro, 1980.

López Arroyo, Manuel, "Los dos siglos de existencia del Observatorio Astronómico de Madrid", Doscientos años del Observatorio Astronómico de Madrid, Madrid, Asociación de Amigos del Observatorio Astronómico de Madrid, 1992, páxs. 1-26.

López López, Roberto, "De la cultura material a la cultura letrada", Historia de la Galicia Moderna: siglos XVI-XIX, Santiago de Compostela, Servizo de Publicacións e Intercambio Científico da Universidade de Santiago de Compostela, 2012, páxs. 359-406.

Manso Porto, Carmen, Domingo Fontán Rodríguez [en liña], dispoñible en $<$ http://dbe.rah.es/ biografias/17619/domingo-fontan-rodriguez $>$ [Consulta 08/02/2020]. 
Méndez Martínez, Gonzalo, Domingo Fontán, Santiago de Compostela, Dirección Xeral de Promoción Cultural, Xunta de Galicia, 2005.

Rey Castelao, Ofelia, "Espacio, Historia e Identidad de Galicia”, Historia de la Galicia Moderna: siglos XVI-XIX, Santiago de Compostela, Servizo de Publicacións e Intercambio Científico da Universidade de Santiago de Compostela, 2012, páxs. 15-38.

Sagra y Peris, Ramón de la, “Observaciones físicas hechas por D. Ramón Sagra en el Océano Atlántico, durante su viage de La Coruña a La Habana", Memorias de la Sociedad Económica de la Habana, 46 (1823), páxs. 209-239.

Sisto Edreira, Rafael, e Losada Sanmartín, María Luisa, Historia da Física na Universidade de Santiago de Compostela, Santiago de Compostela, Servizo de Publicacións e Intercambio Científico da Universidade de Santiago de Compostela, 2009.

Vigo Trasancos, Alfredo (dir.), Galicia y el siglo XVIII: planos y dibujos de arquitectura y urbanismo (1701-1800), A Coruña, Fundación Barrié, 2011.

Vila Fariña, Xose Lois, Vida y obra de Domingo Fontán, Pontevedra, 2004. 
